http://jmscr.igmpublication.org/home/ ISSN (e)-2347-176x ISSN (p) 2455-0450

crossref DOI: https://dx.doi.org/10.18535/jmscr/v8i1.44

Journal Of Medical Science And Clinical Research

\title{
Study on Foreign Bodies in Aerodigestive Tract in Tertiary Care Hospital
}

\author{
Dr Reshma ${ }^{*}$, Dr S.Suryaprakasa Rao ${ }^{2}$, Dr B Nageswara Rao ${ }^{3}$, Dr K.V.Madhavi Latha ${ }^{4}$ \\ ${ }^{1}$ Junior Resident of ENT, Andhra Medical College, Visakhapatnam, India \\ ${ }^{2}$ Professor of ENT, Andhra Medical College, Visakhapatnam, India \\ ${ }^{3}$ Assistant professor of ENT, Andhra Medical College, Visakhapatnam, India \\ ${ }^{4}$ Senior Consultant, Department of Gynecology, Visakhapatnam, India \\ *Corresponding Author \\ Dr Reshma \\ Junior Resident of ENT, Andhra Medical College, Visakhapatnam, India
}

\begin{abstract}
Background: The foreign bodies can be either 1) Endogenous i.e, substance within the body 2) Exogenous foreign bodies a) Organic, b) Inorganic. The route of entry of foreign bodies into the aerodigestive tract is through nasal cavity or oral cavity.

The incidence of endogenous foreign bodies is rare. These are usually secretions in the tracheobronchial tree. The exogenous foreign bodies could be entered by either swallowing or aspiration. These substances are part of the food items i.e. peanuts, fish bones, seeds, chicken bones. Rest of the foreign bodies are part of substances, with which human beings come in contact in daily life which are accidentally aspirated or swallowed by children. These include buttons, coins, nuts, safety pins, nails and some metallic objects ${ }^{[1]}$.

Materials and Methods: The material is chiefly those patients who attended to out-patient department of ENT and casualty of King George Hospital, Visakhapatnam, with a history of foreign body aspiration or ingestion. In this 87 cases attending King George Hospital and Govt. ENT hospital from March, 2017 to March, 2019 were reviewed. Heamatological Examination, Urine Examination and Radiology are conducted on the 87 patients. The foreign bodies are removed with foreign body forceps depending upon the nature of the foreign body and progress was recorded.

Results: Most of the patients in the study group were of 0 to 3 years of age, most common type of foreign body are chicken bone, mutton bone and coins.

Conclusion: Carelessness in the preparation of food and feeding the children, hasty drinking and eating up the drinks and foods are most common etiological factors. The prognosis of foreign bodies after removal is good and none of the cases suffered from any complications in the immediate and late postoperative period.
\end{abstract}

Keywords: Foreign Bodies, Radiology, Chicken bones, Coins, aerodigestive tract.

\section{Introduction}

Majority of the foreign bodies in aerodigestive tract are usually get impacted at narrow sites of the tract. In the nose, nasal valve region being narrowest one, foreign body impaction is more common at this site. Foreign bodies in nasopharynx are rare. They may reached from food passages, while vomiting or during efforts of digital removal. Foreign bodies like fish bones are usually lodged in the fleshy areas like tonsils and base of the tongue and posterior pharyngeal wall. 
In the larynx, subglottis is the narrowest part. foreign body impaction most common at the site. The foreign bodies are usually entered in the sagittal plane as that of rimaglottidis, because of larger anterior posterior diameter of larynx. Majority of foreign bodies in trachea bronchial tree enter the right main bronchus, because, it is wider, shorter and more vertical than left main bronchus.

In the hypopharynx the cricopharynx is the narrowest part foreign bodies are usually get lodged at this site. Foreign bodies are usually entered in the coronal plane, because of larger transverse diameter of hypopharynx.

If the foreign body passed beyond cricopharynx, it usually enters into oesophagus.

Once foreign body enters into the oesophagus, it is usually entered into the stomach. However, if the foreign bodies are usually large, or with rough surfaces, they usually get impacted at other sites of oesophageal constrictions.

\section{Materials and Methods}

The material is mainly those patients who attended to out-patient department of ENT and casualty of King George Hospital, Visakhapatnam, with a history of foreign body aspiration or ingestion. In this 87 study cases attending Govt ENT Hospital from March, 2017 to March, 2019 were reviewed.

Every case of foreign body thoroughly taken the history, the type of foreign body, duration of it and the symptoms complained of by the patient like nasal obstruction, foul smelling nasal discharge, dysphagia, odynophagia, halitosis, dysponea and stridor and the type of intake either due to accidental aspiration or direct ingestion were noted. In the process the patients are investigated haematologically and radiologically.

\section{Heamatological Examination}

Hemoglobin, total RBC, total WBC count were done in all relevant cases to assess the general condition of the patient.

\section{Urine Examination}

This was carried out to explore systemic diseases like diabetes mellitus and renal disorders to assess the preoperative fitness for general anesthesia.

\section{Radiography}

$\mathrm{X}$-ray of chest posterior-anterior view to find out the site of impaction of foreign body to assess secondary changes due to presence of the foreign body are taken. Post-operative check x-rays are taken 48 hours after endoscopic revival of foreign body to assess the condition of the lungs ${ }^{[2]}$.

$\mathrm{X}$-ray neck lateral view to find out foreign body impaction in the larynx and hypopharynx are taken.

Age group of 1 to 12 years are included in the study.

\section{Treatment}

Every case of suspected foreign body aspiration or ingestion is subjected to rigid endoscopy under general anesthesia. The foreign bodies were removed with foreign body forceps depending upon the nature of the foreign body and progress was recorded.

\section{Results}

Table 1: Age Distribution

\begin{tabular}{|l|c|c|}
\hline Age & No Of Cases & Percentage \\
\hline 0-3 Years & 60 & $67.5 \%$ \\
\hline 4-6 Years & 18 & $21.6 \%$ \\
\hline 7-9 Years & 3 & $3.6 \%$ \\
\hline 10-12 Years & 6 & $7.2 \%$ \\
\hline Total & 87 & $100 \%$ \\
\hline
\end{tabular}

\section{AGE INCIDENCE}

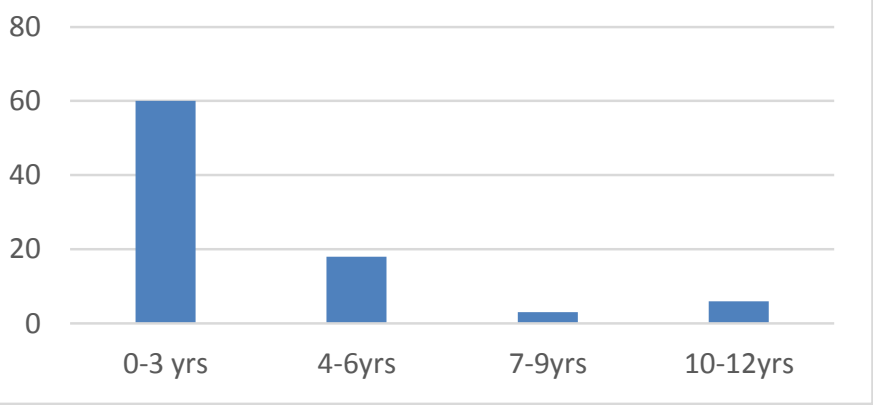


Graph Showing Sex Incidence

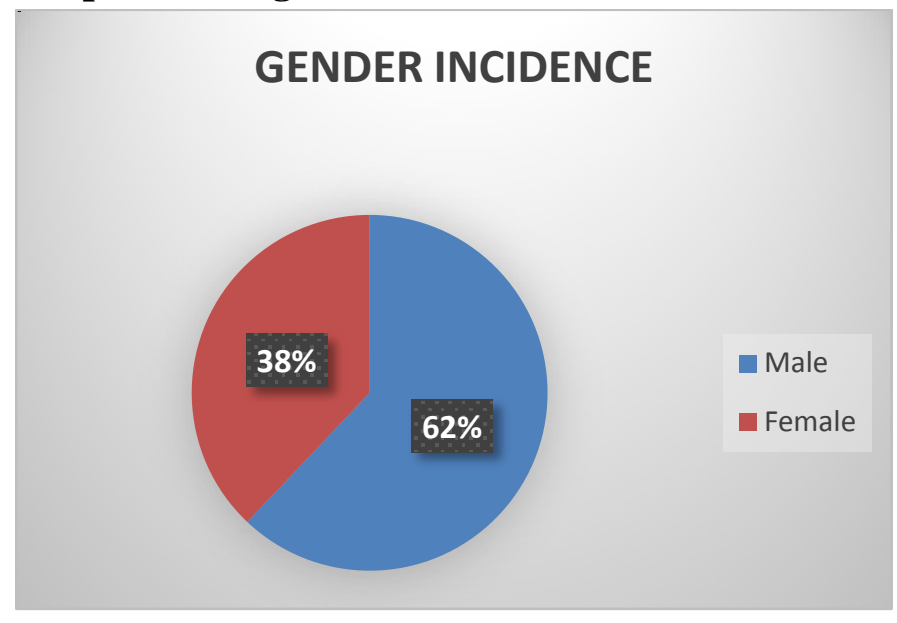

Table 2: Types of Foreign Bodies

\begin{tabular}{|l|c|}
\hline Type & No Of Cases \\
\hline Chicken Bones & 28 \\
\hline Mutton Bones & 24 \\
\hline Coins & 20 \\
\hline Fish Bones & 8 \\
\hline Plastic Heads & 3 \\
\hline Orange Seed & 2 \\
\hline Metallic Pail & 2 \\
\hline Clamp Pin & 1 \\
\hline Safety Pin & 1 \\
\hline Ear Stud & 1 \\
\hline Rubber Piece & 1 \\
\hline Chalk Piece & 1 \\
\hline Metal Pen Tip & 1 \\
\hline
\end{tabular}

Types of foreign bodies

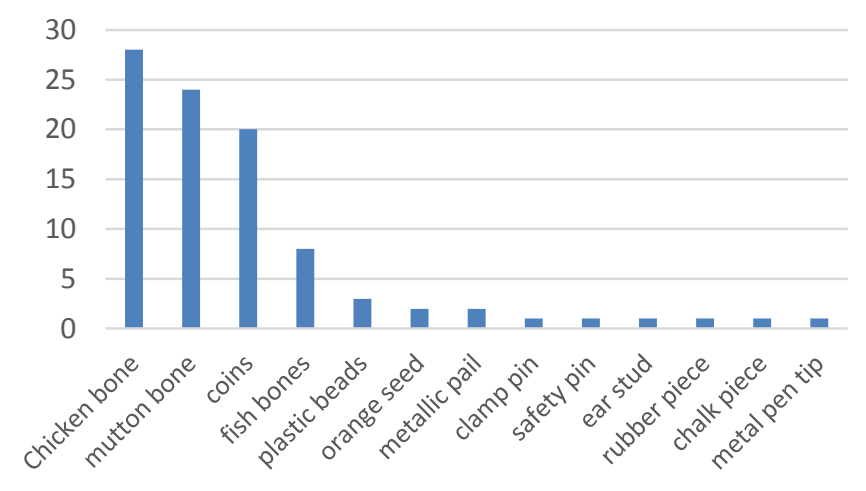

Table 3: Radiological Examination of Foreign Bodies in the Aerodigestive Tract

\begin{tabular}{|c|c|c|}
\hline $\begin{array}{c}\text { Radio Opaque } \\
\text { Foreign Bodies }\end{array}$ & $\begin{array}{c}\text { Non- Radio Opaque } \\
\text { Foreign Bodies }\end{array}$ & Total \\
\hline $\mathbf{5 0}$ & $\mathbf{3 7}$ & $\mathbf{8 7}$ \\
\hline
\end{tabular}

Table 4: Site of Impaction of Foreign Body

\begin{tabular}{|l|c|}
\hline Site & No Of Cases \\
\hline Nose & 12 \\
\hline Nasopharynx & 0 \\
\hline Oropharynx & 14 \\
\hline Hypopharynx & 20 \\
\hline Oesophagus & 15 \\
\hline Larynx & 2 \\
\hline Trachea & 0 \\
\hline Right Bronchus & 14 \\
\hline Left Bronchus & 8 \\
\hline
\end{tabular}

\section{Discussion}

Modern techniques of endoscopic removal of bronchial foreign bodies developed from the advances made in the early part of the century by Chevallier Jackson, who reduced the mortality of removal of foreign bodies from $20 \%$ to approximately $2 \%$. He achieved $98 \%$ of success rate of bronchoscopic removal of foreign bodies ${ }^{(6)}$ All the procedures performed under general anesthesia.

The problem of dealing foreign bodies in the food passages and allied complications also has been simplified with the advent of modern anesthesia and illumination sources. Majority of the complications that occur due to foreign bodies in the aerodigestive tract are prevented by quick approach to the patient, efficient diagnosis by radiology and endoscopic techniques, and proper antibiotic therapy.

In this observational study, patients attending during the period from 2017 to 2019 to ENT Department were taken into consideration. The total number of patients attended during the period are 87. For all cases proper history was taken, requisite investigation are done and subsequent management undertaken depending upon the site of impaction of foreign body in the aerodigestive tract.

During the investigation the following were noted:

1. In different studies, the maximum incidence of inhalation or ingestion of foreign bodies occurs between the age of $1 \& 3$ years. These are in correspondence with our study.

2. Boys are more likely to inhale or ingest foreign bodies than girls by almost at the 
ration of 2:1. In our series about $60 \%$ of foreign bodies were in males and remaining $40 \%$ in females.

3. Most of the patients in the study are from low socio-economic status.

4. Types of foreign bodies: In children peanuts and metallic objects are major foreign bodies, while in adults chicken bones, fish bones and dental prosthesis are major foreign bodies that are found. In our series organic foreign bodies constitute $25 \%$ and inorganic foreign bodies are $75 \%$ metallic objects.

5. In $85 \%$ of the patients a positive history of aspiration was obtained. In children, it is usually due to accidental aspiration, when objects are kept into the mouth playfully.

6. One symptom of the triad- coughing, choking and wheeze are present in $90 \%$ of the patients with foreign body aspiration.

\section{Radiological Diagnosis}

X-ray examination of aerodigestive tract is an important investigation in the detection of foreign bodies. Antero-posterior views of chest in expiration and inspiration should be obtained. CT studies may help to show a foreign body not seen with conventional methods.

In our study, it is found that only $60 \%$ of the cases were radiologically positive in foreign bodies in aerodigestive tract, the remaining $40 \%$ of the cases have radiological changes secondary to the obstructive nature of foreign body in the aerodigestive tract.

In our study 3\% foreign bodies were impacted in the larynx. Virtually no tracheal foreign body is encountered in the trachea. 35\% of foreign bodies are found in the right main bronchus and in the left bronchus an incidence of 5\% was noted. In the oropharynx $19 \%$ if foreign bodies impacted at the base of tongue and posterior pharyngeal wall. $20 \%$ of foreign bodies were lodged at the hypopharynx just above the cricopharyngeal junction. $24 \%$ of foreign bodies were impacted in the middle third of the oesophagus. $8 \%$ of cases were presented with foreign body impaction in the nasal cavities.

\section{Management}

Impacted foreign bodies in the nasal cavities especially nearer to the choana are best removed under general anesthesia. Foreign bodies like fish bones which are usually impacted in the tonsil, base of tongue and posterior pharyngeal wall were removed under good illumination. Foreign bodies in the hypopharyngeal region were removed by oesophageal speculum under general anesthesia. In the foreign bodies of tracheobronchial tree, bronchoscopy was done with storz rigid cold light bronchoscope. The size of the bronchoscope was chosen depending on the age of the patient. After removing the foreign body the entire tracheobronchial tree is re-examined for any remains of foreign body or another foreign body $^{[8]}$.

Foreign bodies in the oesophagus were removed under general anesthesia. For removal of sharp objects utmost care was taken to prevent injury to mucosa of oesophagus.

\section{Conclusion}

It was observed in the present study that foreign bodies in aerodigestive tract is not an uncommon condition. Most of the cases are from low socio economic group. Carelessness in the preparation of food and feeding the children, hasty drinking and eating up the drinks and foods are most common etiological factors.

Most of the foreign bodies are organic in nature, found in normal diet. Inorganic foreign bodies are common household objects like pins, nails and glass beads etc. In children metallic objects like safety pins and nails are common.

Majority of foreign bodies in the study are radiologically positive. Regarding foreign bodies in the tracheobronchial tree above $65 \%$ are in the right main bronchus which correlates with observations of Chevallier Jackson, who states that, foreign bodies are common in right main bronchus as it is short, wide and makes less angle 
with the trachea. About foreign bodies in the hypopharynx $70 \%$ are impacted in the cricopharynx $^{[1]}$.

The prognosis of foreign bodies after removal is good and none of the patients suffered from any complications are post-operative sequelae.

Early detection by meticulous history, imaging modality, and prompt management remains the basis for favourable outcome. Prompt endoscopic intervention is the gold standard for all complicated or high-risk situations, therefore, educational strategies regarding safe behaviours have a key role inprevention of aerodigestive tract foreign bodies. ${ }^{[9]}$

\section{References}

1. Chevalier Jackson \&Chavalier L Jackson: Diseases of Ear, Nose, and Throat.

2. Edward, B. Benedict, A.B.; Endoscopy

3. John Jacob Ballenger: Disease of Nose, Throat, Ear, Head, and Neck.

4. Logan Turner: Diseases of Ear, Nose, and Throat. 10th Edition.

5. Moskowitz, F.Rodgers B.M: Archives of Otolaryngology.

6. Rothman, B.F and Boeck Man, C.R: Annuals of Otology, Rhinology and Laryngology.

7. Scott Brown's Otolaryngology. 6th Edition, 1997

8. Hollinger P.H. and Hollinger, L.D: Chest.

9. Gupta, Richa, and V K Poorey. "Incidence of foreign bodies in aerodigestive tract in Vindhya region: our experience." Indian journal of otolaryngology and head and neck surgery: official publication of the Association of Otolaryngologists of India vol. 66,2 (2014): 135-41. doi:10.1007/s12070-013-0644-8. 